\title{
Predicting the response of seven Asian glaciers to future climate scenarios using a simple linear glacier model
}

\author{
Diandong Ren ${ }^{1}$ and David J. Karoly ${ }^{2}$ \\ Received 22 May 2007; revised 12 November 2007; accepted 7 December 2007; published 11 March 2008.
}

[1] Observations from seven Central Asian glaciers $\left(35-55^{\circ} \mathrm{N} ; 70-95^{\circ} \mathrm{E}\right)$ are used, together with regional temperature data, to infer uncertain parameters for a simple linear model of the glacier length variations. The glacier model is based on first order glacier dynamics and requires the knowledge of reference states of forcing and glacier perturbation magnitude. An adjoint-based variational method is used to optimally determine the glacier reference states in 1900 and the uncertain glacier model parameters. The simple glacier model is then used to estimate the glacier length variations until 2060 using regional temperature projections from an ensemble of climate model simulations for a future climate change scenario (SRES A2). For the period 2000-2060, all glaciers are projected to experience substantial further shrinkage, especially those with gentle slopes (e.g., Glacier Chogo Lungma retreats $\sim 4 \mathrm{~km}$ ). Although nearly one-third of the year 2000 length will be reduced for some small glaciers, the existence of the glaciers studied here is not threatened by year 2060. The differences between the individual glacier responses are large. No straightforward relationship is found between glacier size and the projected fractional change of its length.

Citation: Ren, D., and D. J. Karoly (2008), Predicting the response of seven Asian glaciers to future climate scenarios using a simple linear glacier model, J. Geophys. Res., 113, D05103, doi:10.1029/2007JD008997.

\section{Introduction}

[2] The fate of glaciers under a warming climate has been a recurring topic in both the refereed scientific literature and in the popular media. The worldwide retreat of many glaciers during the past few decades is frequently mentioned as a clear and unambiguous sign of global warming [Dyurgerov and Meier, 2000; Folland and Karl, 2001].

[3] This paper uses the temperature projections from coupled general circulation models (CGCMs) to estimate glacier melting and the associated glacier length fluctuations in the upcoming 50 years. Here, we present predictions of the future terminus fluctuations for seven Asian glaciers, based on a simple linear model linking glacier length fluctuations to temperature variations, as presented by Oerlemans [2005]. This linear model depends on two parameters: climate sensitivity $(c$, the decrease in equilibrium glacier length per degree temperature increase) and response time $(\tau$, the time a glacier needs to approach a new equilibrium state). Available CGCM simulated temperature series usually do not start from the reference states (temperature anomaly $T_{\text {ref }}^{\prime}$ and glacier length perturbation $L_{\text {ref }}^{\prime}$ by Oerlemans [2005] and used interchangeably with $T_{0}$ and $L_{0}$ henceforth). Oerlemans [2005] chose the year 1950 as the reference state (i.e., $T^{\prime}=\left(T-T_{r e f}\right)=0$ and $L^{\prime}=\left(L-L_{r e f}\right)=0$

\footnotetext{
${ }^{1}$ School of Meteorology, University of Oklahoma, Norman, Oklahoma, USA.

${ }^{2}$ School of Earth Sciences, University of Melbourne, VIC, Australia

Copyright 2008 by the American Geophysical Union. 0148-0227/08/2007JD008997
}

at year 1950). To make it suitable for using CGCM simulated temperature as forcing for a forward integration, instead of directly using glacier parameters as used by Oerlemans [2005], we estimate $c$ and $\tau$ together with the glacier length and reference temperature values at the initial integration time. An adjoint method [Errico, 1997; Ren, 2006] is applied in the estimation because it is ideally suited for dealing with sparse observational data spread irregularly in time, exactly the current situation for glacier length records. This approach allows the uncertain parameters $c$ and $\tau$ for the simple glacier model to be estimated for an arbitrary glacier given observed glacier length and temperature variations.

[4] If the forward model is exact and there is no observational error, four data at four times are enough for retrieval of the four constant parameters. In practice, we may need more information to reduce the uncertainty caused by model structural limitations and observational errors. Here, we use both the Hadley Centre-Climatic Research Unit of the University of East Anglia (HadCRUT3, Brohan et al. [2006]) observed temperatures and the ensemble mean temperature data from a climate model simulation experiment called the 20th Century Climate in Coupled Models (20C3M simulations) as input to the adjoint simulator to optimally adjust the four initial estimated values for $c, \tau, T_{0}$ and $L_{0}$. Whereas differences of climate sensitivity and response time of glaciers are taken into account for individual glaciers, the time variations of temperature used for every glacier are the same area-average values over a region covering central Asia $\left(35-55^{\circ} \mathrm{N} ; 70-\right.$ $\left.95^{\circ} \mathrm{E}\right)$. 
Table 1. Geographic Characteristics of the Seven Asian Glaciers

\begin{tabular}{|c|c|c|c|c|c|c|}
\hline Name & Location (lat;lon) & Slope angle (rad.) & Area, $\mathrm{km}^{2}$ & Length, km & Eleva. Range (max-mean-min), m & Sources \\
\hline $\begin{array}{l}\text { Bolshoy } \\
\text { Maashey }\end{array}$ & $\left(50.12^{\circ} \mathrm{N} ; 87.58^{\circ} \mathrm{E}\right)$ & 0.241 & 16.0 & 8.2 & $4180-3170-2223$ & $\begin{array}{l}\text { World Glacier } \\
\text { Monitoring Service } \\
\text { (WGMS) }\end{array}$ \\
\hline $\begin{array}{l}\text { Chogo } \\
\text { Lungma }\end{array}$ & $\left(36^{\circ} \mathrm{N} ; 75^{\circ} \mathrm{E}\right)$ & 0.1 & 320.0 & 45.1 & $7291-4600-2750$ & WGMS \\
\hline Geblera & $\left(50.13^{\circ} \mathrm{N} ; 87.58^{\circ} \mathrm{E}\right)$ & 0.232 & 10.0 & 5.0 & $3650-3170-2500$ & WGMS \\
\hline Maliy Aktru & $\left(50.08^{\circ} \mathrm{N} ; 87.75^{\circ} \mathrm{E}\right)$ & 0.344 & 3.8 & 4.4 & $3714-3200-2229$ & WGMS \\
\hline Minapin & $\left(36.18^{\circ} \mathrm{N} ; 74.58^{\circ} \mathrm{E}\right)$ & 0.261 & 60.5 & 18.5 & $7266-4350-2475$ & WGMS \\
\hline Rodzevicha & $\left(47^{\circ} \mathrm{N} ; 91^{\circ} \mathrm{E}\right)$ & 0.305 & 10.0 & 5.0 & $3700-3000-2200$ & $\begin{array}{l}\text { Galakhov and Mukhamedov } \\
1999 \\
\text { (GM99) }\end{array}$ \\
\hline Sapozhnikova & $\left(47.17^{\circ} \mathrm{N} ; 91.17^{\circ} \mathrm{E}\right)$ & 0.284 & 10.0 & 5.1 & $3700-3000-2300$ & GM99 \\
\hline
\end{tabular}

[5] Oerlemans et al. [1998] attempted to model future glacier behavior by first calibrating models from historical glacier length records. They then assumed several scenarios of future climate and discussed the response of the glaciers. Ohmura et al. [1996] studied the Greenland ice sheet mass balance using a high-resolution GCM (not fully coupled due to technical limitations a decade ago). They found the air temperature simulation is "extremely good". Among the important conclusions are the opposite reactions to climate warming from Greenland and Antarctica. The partial cancellation of the two ice sheets makes the valley glaciers an important contributor to sea level fluctuations in the near future [Meier et al., 2007]. Current CGCMs are believed capable of providing future climate scenarios of considerable fidelity. However, due to the coarse horizontal resolution (about 200-400 km), CGCMs do not represent the detailed climatology of the mountain areas. Through inverting a linear response equation and driving it with 169 glacier length records from different parts of the world, Oerlemans [2005] reconstructed historical temperature time series from 1600 to 1990 . He found that the warming signals extracted from glaciers at low and high elevations are similar and further asserted that the warming in the lower troposphere appears to be elevation independent. Thus the topography appears not to be an important issue for estimating glacier variation from warming using this linear model, because the temperature forcing is in the form of anomalies (departures from climatological values), not actual temperature values. Oerlemans [2005] also noticed that the warming was notably coherent over the globe and that precipitation changes were not a major contributor to the overall long-term glacier length variations. Ren and Karoly [2006] reported good agreement between glacierinferred, observed and modeled temperature variations in the different glacier regions considered by Oerlemans [2005]. These findings form the basis for using CGCM temperature anomalies to estimate future glacier length fluctuations. Compared with possible variations in net radiation and precipitation in the 2001-2060 period, the temperature variations are assumed to play a first-order role in the glacier melting [see, e.g., Oerlemans, 1994, 2005].

\section{Data}

[6] The seven central Asian glaciers studied give a good representation of the climate regimes of the Central Asian mountain area. The Minapin and Chogo Lungma glaciers are close to each other and are located in the wetter Monsoonal region. Rodzevicha and Sapozhnikova glaciers are also close to each other but located in cold arid Altais. Maliy Aktru, Geblera and Bolshoy Maashey glaciers are clustered together in an arid region even further to the north. The slope of the Chogo Lungma is much smaller than the remaining six glaciers. The wetter environment of Minapin and Chogo Lungma probably contributes to their relatively larger climate sensitivity [Meier, 1984]. Supporting online material of Oerlemans [2005] provides $c$ and $\tau$ values for every glacier used in this study, which is a useful reference for testing our retrieval scheme. Details of the seven Asian glaciers, including slope, area, length, elevation range, and mean elevation are listed in Table 1.

[7] In this study, temperature data from CGCMs are used to estimate the glacier climate sensitivity, response timescale and reference states, and to predict future glacier length perturbations. Specifically, the model parameters are inferred using the observed glacier length and the temperature series from 20C3M runs. Predictions of future glacier length are based on the transient climate simulations under one high impact (A2) scenario described in the Special Report on Emissions Scenarios (SRES, Nakicenovic and Swart [2000]). To reduce uncertainty caused by different physical parameterizations of subgrid scale phenomena, multiple ensemble runs of SRES A2 and 20C3M are used.

[8] Monthly mean near surface air temperature data from nine climate models developed by seven different research groups have been used in this study. Simulations with these models were run as part of a coordinated series of simulations by the modeling centers for the IPCC Fourth Assessment Report. Their IPCC IDs are: NCAR CCSM3 (CCS), CGCM3.1 (CGCT47), ECHAM5 (ECH), GFDL CM2.0 and CM2.1 (GFDL2.0/2.1), MIROC3.2 medres(MME), MRI GCM-Iib (MRI), NCAR PCM (PCM), and UKMO-HadCM3 (HCM). Details of these models, including their resolution in the ocean and atmosphere, acronyms, and original references, can be found in Table 1 of Ren and Karoly [2006]. All models include representations of the key physical processes in the atmosphere and the ocean, as well as sea ice and land surface processes. Monthly mean near surface observed air temperature from HadCRUT3 [Brohan et al., 2006] are given as temperature anomalies (relative to the 1961-1990 reference period) distributed over 5 degree latitude by 5 degree longitude grid boxes. 
[9] This study involves thirty-three 20C3M runs and thirteen realizations of SRES A2 runs. 20C3M simulations include changes in greenhouse gas concentrations and aerosols as observed in the atmosphere, to represent the changes in anthropogenic radiative forcing of the climate, together with estimated changes in solar irradiance and volcanic aerosols, to represent changes in natural radiative forcing factors. The SRES A2 runs were initiated from the end of the corresponding 20C3M runs (year 2000). The GHG concentrations and various aerosols emissions were changed according the IPCC SRES A2 scenario in the course of the integration. Of the $3320 \mathrm{C} 3 \mathrm{M}$ ensemble runs, 7 are from CCS, 5 from both MRI and CGCT47, 3 from GFDL 2.0, GFDL 2.1, ECH and MME each, 2 from both PCM and HCM. Among the 13 SRES A2 runs, 4 are from CCS, 4 from PCM, 3 from ECH, 1 from GFDL2.0 and 1 from HCM. We used a 100-year simulation length from the 20C3M (1900-1999) and SRES A2 (2000-2099) runs. We believe that the total number of multiensemble runs for the 20C3M and SRES A2 simulations is sufficient to represent the uncertainty in future regional temperature projections from different climate models and to ensure that our interpretations are statistically robust.

[10] The CGCM output used in this research is entirely from the data archive at the Program for Climate Model Diagnosis and Inter-comparison (PCMDI) Coupled Model Intercomparison Project 3 (CMIP3, Gregory et al. [2005]). The model variable used is monthly mean near surface air temperature, a variable slated as one of the highest priority output fields in the CMIP project.

\section{Forward Force-Restore Model and the Retrieval Approach}

[11] The Oerlemans [2005] model is briefly presented to establish a basis for discussion of the application to glacier length variation and the adjoint code needed for optimal determination of the coefficients. A very brief description of the underlying assumptions and theoretical developments of the model are included in this section. The reader is referred to Oerlemans [2005] for more thorough discussion of the forward model. The model describes changes in glacier length through time as a function of several parameters that account for a temperature perturbation, glacier sensitivity index and response time.

$$
\frac{d L^{\prime}(t)}{d t}=-\frac{1}{\tau}\left[c T^{\prime}(t)+L^{\prime}(t)\right],
$$

where $L^{\prime}$ is the glacier length with respect to a reference state, $T^{\prime}$ is a temperature perturbation (annual mean) with respect to a reference state, $c$ is climate sensitivity, and $\tau$ is the e-folding time. Climate sensitivity $c$ and response time $\tau$ are modeled as functions of climatological annual precipitation, the mean surface slope of the glacier, the altitudinal mass balance gradient, and the reference glacier length. The notation used here agrees with Oerlemans [2005] and will be explicitly stated otherwise.

[12] A formal solution to the forward model of Oerlemans [2005] is

$$
L^{\prime}(t)=L_{0} e^{-\frac{t}{\tau}}-\frac{c}{\tau} \int_{0}^{t} T^{\prime}(u) e^{-\frac{t-u}{\tau}} d u
$$

where $L_{0}$ is the glacier length perturbation at the initial time (i.e., $L_{0}^{\prime}=L(\mathrm{t}=0)-L_{r e f}$, and we omitted the prime for convenience), and $u$ is a dummy variable for time integration. The first term on the right hand side is a time decaying term with e-folding timescale of $\tau$. The second term involves the force and restore of a glacier to temperature forcing over time period $t$. The coefficient $c$ can also be viewed as a weighting average on the temperature perturbation. One special case has important implications for glacier fate under a warming climate. For a constant forcing $T_{c}^{\prime}$, which is analogous to a stabilized temperature to be realized some time in the future, the glacier length perturbation approaches $-c T^{\prime}{ }_{c}$ with time. In this sense, the ultimate fate of the glaciers is determined by the new equilibrium temperature within the framework of global warming. If the equilibrium size corresponding to the prevailing climatic conditions is close to zero, this glacier may simply disappear [Oerlemans et al., 1998].

[13] The equation (2), as a linear system, changes the frequency spectrum of the input forcing signal (temperature perturbations). The output signal delays the phase (depends on $\tau$.) and reduces the amplitude of high frequency variations. Except for surging glaciers, for which the main part of its terminus fluctuation is not connected with global warming, the linear model gives a satisfactory description of the relationship between temperature anomalies and the glacier length fluctuations (Oerlemans, personal communication, 2006). Equation (2) indicates that an error in estimating the reference states $L_{0}$ will decay at e-folding time $\tau$ but error on $T^{\prime}{ }_{r e f}$ may persist. Based partially on this consideration, we estimate $L_{r e f}^{\prime}\left(L_{0}\right)$ and $T^{\prime}{ }_{r e f}$ using an optimal determination.

[14] Adjoint (adjoint to equation (1)) based variational data assimilation and/or retrieval systems seek to minimize the mismatch between observations distributed over a period of time (called the assimilation window) and the prediction of a forward forecast model [LeDimet and Talagrand, 1986; Talagrand and Courtier, 1987]. A cost function, typically of a quadratic form, measures such a misfit. In our circumstance, the cost function $(J)$ is defined as the root mean square difference between observed and predicted glacier lengths $J(U)=\sum_{i=1}^{N}\left(\frac{L^{\prime, O}-L^{\prime f}(U)}{\sigma_{L^{\prime}}^{O}}\right)^{2}$. Here $N$ is the number of observations during an assimilation period. The control variable $U$ is now a vector containing four components: $\tau, c, T_{\text {ref }}$ and $L_{r e f}^{\prime}$. The $\sigma_{L^{\prime}}{ }^{O}$ represent the relative confidence accredited to each observation (superscript $o$ ) and prediction (superscript $f$ ) pair, which are typically the standard deviation of the observational error in glacier length perturbations. The absolute value of $\sigma_{L^{\prime}}{ }^{O}$ is not vital because we do not involve background terms in the cost function definition. The initial condition of the forecast model is adjusted, starting from an initial guess, so as to minimize the cost function. When the variables defining the initial conditions are not directly measured, such variables are said to be retrieved (from the observed quantities) and the entire procedure is often referred to as a variational or optimal parameter estimation.

[15] Efficient minimization algorithms, such as the conjugate gradient method [Navon and Legler, 1987] used in this study, require the gradient of the cost function with respect to the variables to be adjusted (called control 

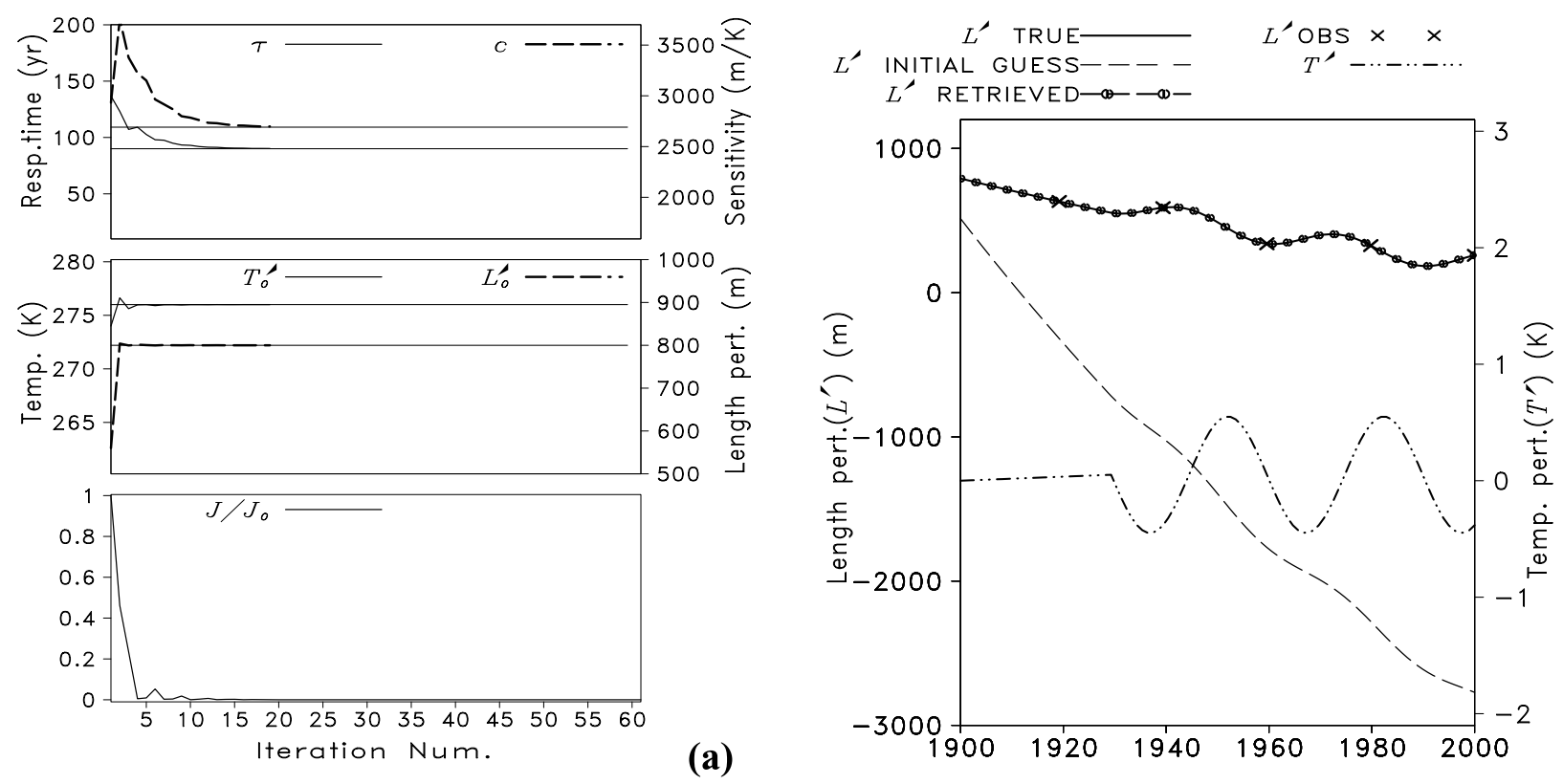

(b)

Figure 1. (a) The parameter retrieval procedure as indicated by how the four parameters approach the true values as iterations increase. The bottom panel is the decrease of the cost-function measured by the RMS between observed and true glacier length perturbations. (b) Comparisons between initial guessed (dashed line), retrieved (line with 'circle-with-vertical bar' marker) and the true (solid line) time series of the glacier length perturbations. Observation data grids are labeled with cross-mark and the temperature forcing (dot dashed line) uses the secondary axis.

variables), and the gradient can be efficiently obtained by a backward-in-time integration of the adjoint model. In a more general system, the control variables can include other parameters such as those found in the formulation of the forward model. The basis for an adjoint model applied to land surface modeling can be found in Ren [2006] and references cited therein. In this study we used the case for parameter retrieval. A flowchart of the retrieval procedure can be found on page 73 of Ren [2004].

\section{Sensitivity of the Parameter Estimation}

[16] Here, we present an objective climatic interpretation of glacier length records from 7 central Asia glaciers. An adjoint inverse model provides the basis for an individual treatment of all length records in estimating four parameters: climate sensitivity, response time, reference temperature, and reference glacier length perturbation.

[17] Observing System Simulation Experiments (OSSEs) are commonly used to test new data assimilation systems or new observation network or platform [see, e.g., Arnold and Dey, 1986; Lord et al., 1997]. With OSSE experiments, simulated observation data are created by model runs. For future observing instruments or platforms, OSSE is the only way to examine the potential impact of their observations. To examine the effectiveness of new data assimilation techniques or systems, OSSE is also a very effective tool because the modeler has full control over the entire system, include data availability and quality. One also knows the truth about the state to be analyzed or retrieved because it is given by the simulation model. Using OSSE, one does not have to worry about any possible error with the simulation model, at least initially, so as to be able to focus on the correctness and quality of the assimilation and/or optimal parameter retrieval system that is developed. For these reasons, we will first present in this section results from OSSE experiments to assess the sensitivity of this approach for estimating the unknown model parameters. Results from real data will be presented in the next one. We first perform OSSEs using model-generated data and starting the retrieval procedure from an erroneous initial guess parameter vector.

[18] The 'correct' parameter values we used in performing the OSSE experiments are $\tau=90$ year, $c=2691 \mathrm{~m} / \mathrm{K}$, $T_{\text {ref }}=276 \mathrm{~K}$ and $L_{r e f}^{\prime}=800 \mathrm{~m}$. The temperature is in the form

$$
T=\left\{\begin{array}{lc}
T_{r e f}+\frac{A t}{30} & 0<t<30 \text { years } \\
T_{r e f}+A-B \sin \frac{\pi t}{15} & 30<t<100 \text { years }
\end{array}\right.
$$

where $A$ equals $0.05 \mathrm{~K}$ and $B$ equals $0.5 \mathrm{~K}$. Forcing is then simply $T-T_{\text {ref: }}$ The analytical form of glacier length perturbation $L^{\prime}$ is actually obtainable from equation (2). However, here we want to address the robustness of our retrieval system. We use the glacier lengths obtained by a forward integration of 100 years, starting from 1900, as the true values of observation. We assume initial guess errors exist on all control variables and start the retrieval procedure from an initial guess of four parameters: $\tau=136.8$ year, $c=$ $2936 \mathrm{~m} / \mathrm{K}, T_{\text {ref }}=276 \mathrm{~K}$ and $L_{r e f}^{\prime}=560 \mathrm{~m}$, which are significantly different from the true values. In other words, they are roughly 1.5, 1.1 and 0.7 times the true values for $\tau$, $c$, and $L_{r e f}^{\prime}$, respectively. The error of $2 \mathrm{~K}$ in the initial guess in $T_{r e f}$ is also significant. 

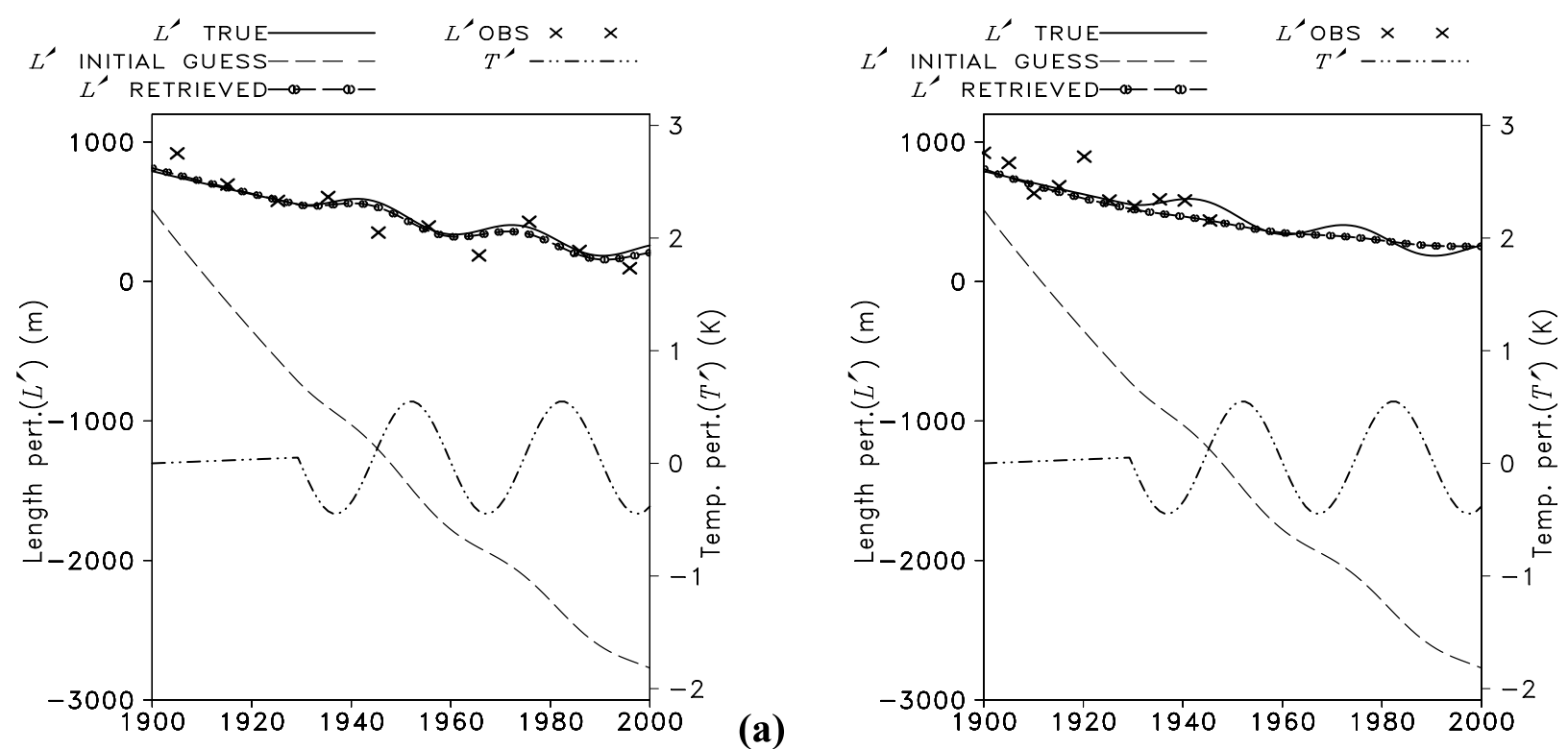

(b)

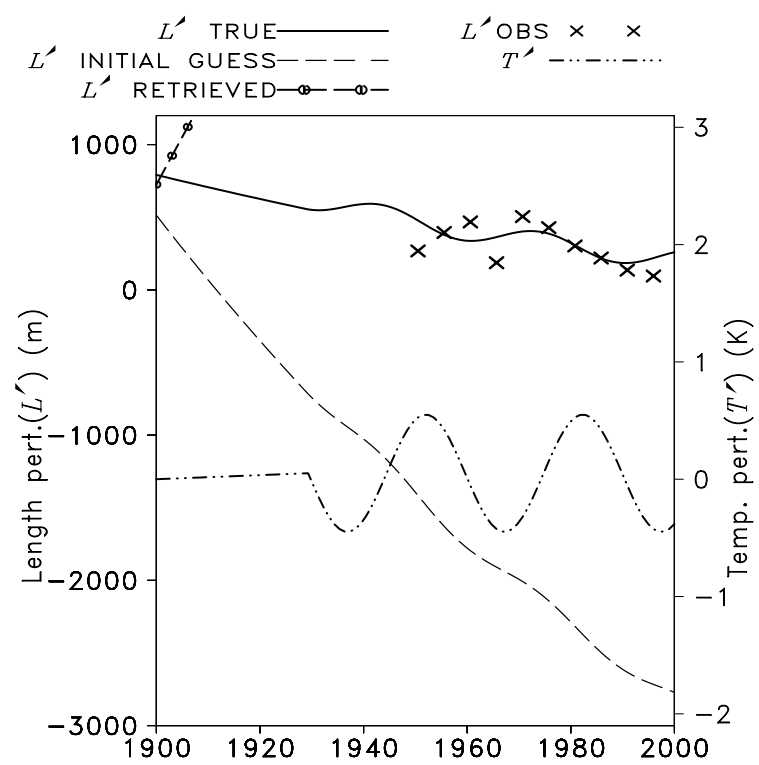

(c)

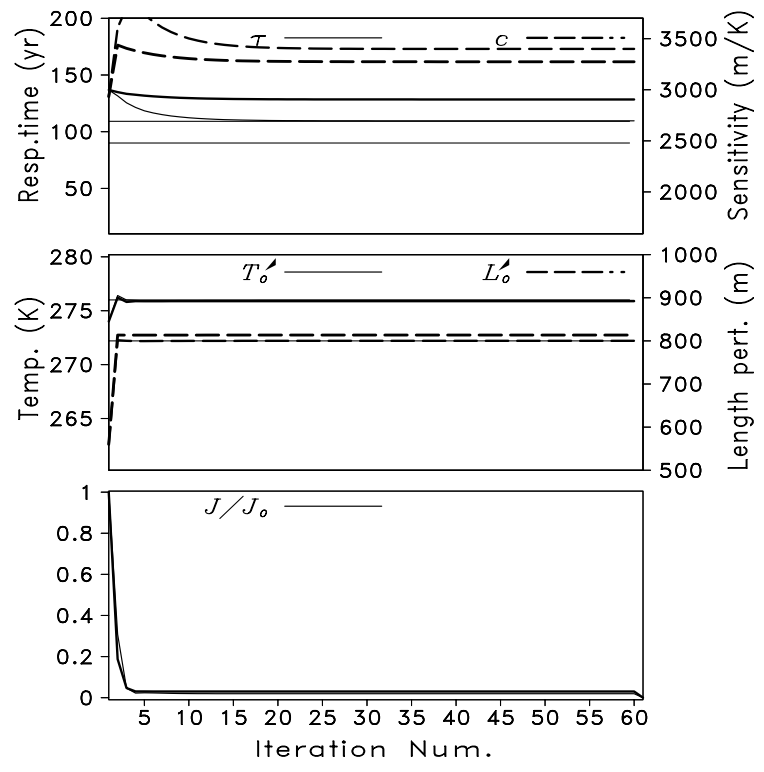

(d)

Figure 2. Comparison between different data availability. Three retrieval experiments with same number of data grids but distributed evenly (a) over the whole 100-year period, (b) over first half 50 years, and (c) over the second half 50 years. (d) A comparison of the retrieval procedure for cases in Figures $2 \mathrm{a}$ and $2 b$.

[19] Because there are only 4 parameters to be determined, the over-determination requirement is readily satisfied. We systematically reduce the observational data availability from 100 individual annual values to only six data values. The retrieval was not significantly affected for OSSEs without added noise on the observations. Here we show the retrieval results obtained from using only 6 data values distributed over the 100 -yearlong assimilation window. As shown in Figure 1a, it takes the optimization scheme merely 5 iterations to converge to $\tau=90.2$ year, $c=2697.7 \mathrm{~m} / \mathrm{K}, T_{r e f}=276 \mathrm{~K}$, and $L_{r e f}^{\prime}=800 \mathrm{~m}$, all close to the true values, as indicated by the fact that the initial guess errors are all reduced to an insignificant amount: 0.21 year for $\tau, 6.7 \mathrm{~m} / \mathrm{K}$ for $c, 0.018 \mathrm{~m}$ for $L^{\prime}$ and 0 for $T_{r e f}$. The root-mean squared error $(\mathrm{rms})$ in glacier length perturbation prediction within the assimilation period was reduced by over 5 orders of magnitude from its initial amount (Figure 1b, bottom panel). The two reference states, $L_{r e f}^{\prime}$ and $T_{r e f}\left(L_{0}^{\prime}\right.$ and $T^{\prime}{ }_{0}$ in the plot), although no corresponding observations for them are assimilated, can also be successfully updated.

[20] Using retrieved glacier parameters, we integrated the forward model one more time to obtain the state estimates. Figure 1b illustrates the vast improvement that is gained in representing the states by assimilating merely the glacier length observations. Although the initial guess trajectory is apparently deviant from the corresponding true trajectory, the retrieved trajectories are nearly indiscernible from the "true" one. 


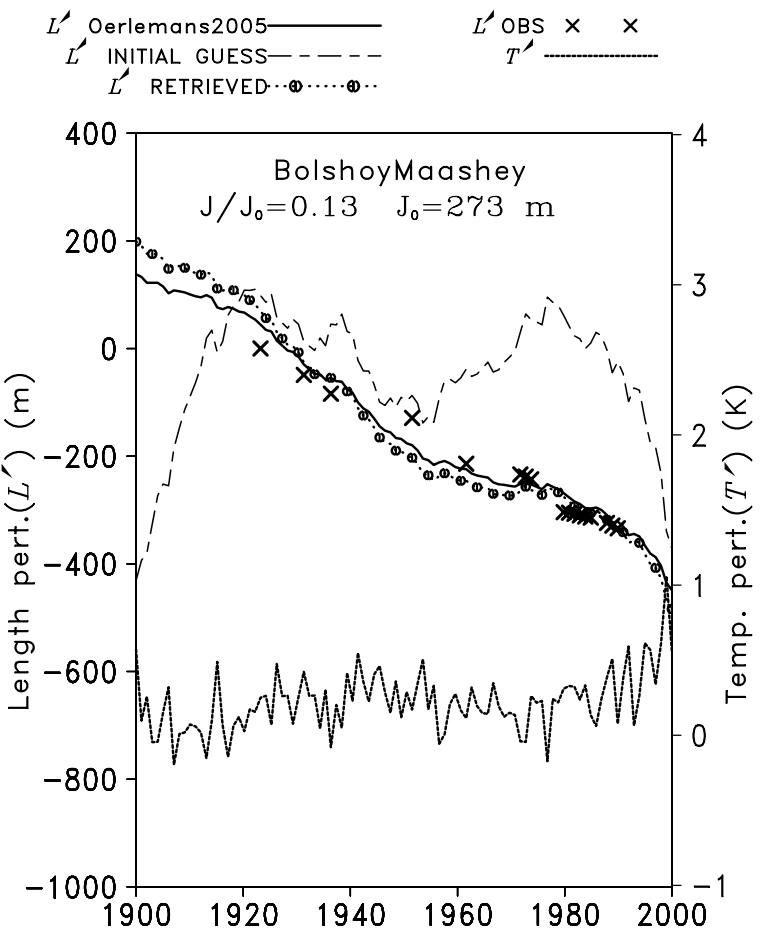

Figure 3. Real data retrieval for Glacier Bolshoy Maashey. Comparisons among glacier length trajectories resulted from prior guessed parameters (dot dashed line); retrieved values (dotted line with markers); and the time series resulted from using Oerlemans [2005] provided parameters (solid line). The observed glacier length perturbations are shown as cross marks. Temperature anomaly is the HadCRUT3 observations (secondary axis, dotted line).

[21] We double the initial guess error magnitudes and find the retrieval is still successful. However, it takes more iterations to converge (figures not shown). In general, the retrieval procedure is robust for reasonable perturbations in the prior guess values. If the perturbations are too large, however, there can be other estimates that reproduce the measured glacier lengths but are different from the actual state of the system (i.e., solution bifurcation). This is especially true for $T_{\text {ref }}$.

[22] Specifically, the initial guess errors in $\tau$ can be as large as 5 times the actual value, or we can just put the initial guess at 50 year or 500 year without much apparent effect on the performance of the optimization scheme. However, due to the manner in which $c$ is used in equation (2), the initial guess error on climate sensitivity should not be that large. We found that our scheme works as long as the initial guess lies between $0.3 \sim 1.5$ times the true value. This range is large and practical considering that it actually brackets the range for all types of glaciers [Oerlemans, 2005].

[23] Robustness to observational errors is more of an issue when using real data, where model error is usually also involved. We tested the robustness of the assimilation scheme by adding zero-mean Gaussian noise of different standard deviations $(s t d)$ to the synthetic observations of $L^{\prime}$. It is hardly surprising that the final degree of closeness as measured by the cost-function degrades with increasing noise level. In fact, for the same initial guess error as presented in the OSSE experiments and a full 100-data value coverage, the parameter retrieval does not work effectively when the noise level surpasses $1000 \mathrm{~m}$ std. The situation worsens as data gets sparser and initial guess errors become larger. However, random error of standard deviation $<100 \mathrm{~m}$ does not affect the retrieval as long as there are more than 12 glacier length observations evenly distributed.

[24] An interesting finding is that, for sparse noisy observations, the distribution of the available observations also makes a difference in the retrieval. Assuming everything else is the same, when the observations are from the later portion (close to year 1999), the retrieval seems to be less successful, and this is especially true for larger $A$ value in equation (3). This is illustrated in Figure 2, where Gaussian noise of $150 \mathrm{~m}$ std is added to the glacier length observations. We compared three cases of retrieval: (a) 9 length observations taken evenly from the whole 100-year period; (b) from the first half 50 years; and (c) from the second half 50 years. All the remaining setting is the same as in Figure 1. We find that (a) and (b) perform similarly in the retrieval of the four parameters and as a result can successfully reproduce the glacier length perturbation time series. However, if observations are all taken from the period with sinusoidal forcing, the retrieval is much worse. It is the climate sensitivity parameter $c$ that is most sensitive to noise level, followed by $T_{0}, \tau$ and $L_{0}$, in this order. If the frequency of the sinusoidal forcing is reduced, the disparity (in information content for retrieval) between these two half-periods is reduced. Further experiments indicate that the magnitude of the sinusoidal component does not play a definitive role in the ease of the retrieval for noisy data. For lower frequency forcing, a larger $B$ value helps retrieval to resist noise, especially for data sparse situations.

\section{Results From Real Data Retrieval}

[25] Based on the understanding from these retrieval sensitivity experiments, we perform the real data retrieval. The retrieved parameters are compared with those provided by Oerlemans [2005]. With these retrieved parameters, we run the forward model integration for an extended period to obtain the future behavior of the glacier length, individually and as a group.

[26] For each glacier with more than six length observations over the past century, we perform parameter retrieval using HadCRUT3 observed temperature anomaly time series (anomalies relative to the 1961-1990 reference period and area-averaged over Central Asia). We can use a common initial guess parameter vector such as $\tau=$ 100 year, $c=1000 \mathrm{~m} / \mathrm{K}, T^{\prime}{ }_{r e f}=0.05 \mathrm{~K}$, and $L^{\prime}{ }_{r e f}=-50$ $\mathrm{m}$ for all glaciers. However, to illustrate the arbitrariness of the initial guess choosing, we deliberately used different initial guess parameters for different glaciers.

[27] For glacier Bolshoy Maashey (Figure 3), our method used here is very successful. Upon convergence, the retrieved glacier length time series is close to those observed (rms error as small as $31 \mathrm{~m}$, while the initial guessed trajectory has an RMS error as large as $273 \mathrm{~m}$ ). This excellent performance can be explained this way: Although the data are not evenly distributed over the whole period, they are concentrated over a period with apparent warming trend, thus satisfying our data requirements for overcoming 

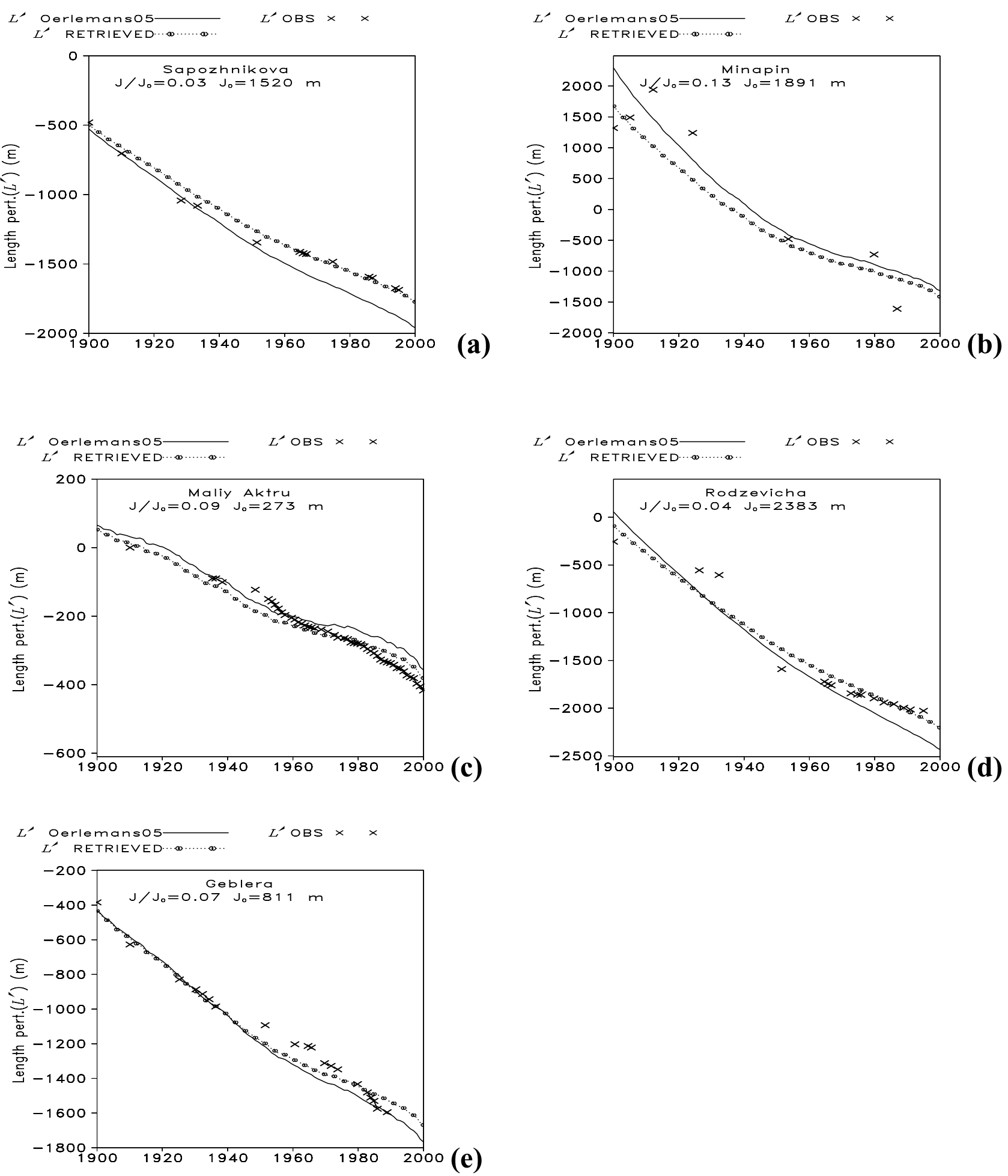

Figure 4. As Figure 3 but for glaciers (a) Sapozhnikova, (b), (c)Maliy Aktru, (d) Rodzevicha, and (e) Geblera.

observational uncertainties. Starting from the reference temperature and glacier length perturbation of Oerlemans [2005], and using the temperature forcing (very close to the HadCRUT3 temperature) therein, the 1900s values are $-0.2 \mathrm{~K}$ and $160.0 \mathrm{~m}$, very close to what we retrieved here: $-0.19 \mathrm{~K}$ and $184 \mathrm{~m}$.
[28] The retrievals for the remaining six glaciers are also satisfactory, as listed in Table 2 and shown in Figure 4, where the common temperature forcing lines are omitted for clarity. Table 2 documents the retrieved parameters with those given by Oerlemans [2005]. The retrieved $c$ and $\tau$ (except for Chogo Lungma, reasons will be detailed later) are reasonably close to the ones provided by Oerlemans 
Table 2. Retrieved Parameters for Each of the Glaciers Studied

\begin{tabular}{|c|c|c|c|c|c|c|c|c|c|c|}
\hline \multirow[b]{2}{*}{ Glacier Name } & \multicolumn{5}{|c|}{ Retrieved } & \multicolumn{5}{|c|}{ Oerlemans [2005] } \\
\hline & $\tau(\mathrm{yr})$ & $c(\mathrm{~m} / \mathrm{K})$ & $T_{0}(\mathrm{~K})$ & $L_{0}(\mathrm{~m})$ & $r m s$ in $L^{\prime}(\mathrm{m})$ & $\tau(\mathrm{yr})$ & $c(\mathrm{~m} / \mathrm{K})$ & $T_{0}(\mathrm{~K})$ & $L_{0}(\mathrm{~m})$ & $r m s$ in $L^{\prime}(\mathrm{m})$ \\
\hline Bolshoy Maashey & 105 & 2500 & -0.19 & 184 & 30.77 & 75 & 2645 & -0.2 & 160.0 & 24.64 \\
\hline Chogo Lungma & 52 & 6000 & -0.0 & -44 & 178.3 & 132 & 5488 & -0.0 & -60.0 & 181.69 \\
\hline Chogo Lungma ${ }^{a}$ & 180 & 6000 & 0.805 & 59.0 & & 132 & 5488 & 0.9 & 80.0 & \\
\hline Geblera & 102 & 2745 & -0.9 & -400 & 61.35 & 80 & 2000 & -1.04 & -403 & 79.83 \\
\hline Maliy Aktru & 80 & 1400 & -0.35 & 66.03 & 27.02 & 78 & 1637 & -0.3 & 80 & 41.47 \\
\hline Minapin & 45 & 2438 & 0.0 & 1600 & 466.0 & 50 & 3000 & -0.56 & 1557 & 430.0 \\
\hline Rodzevicha & 105 & 1652 & -2.4 & 100 & 136.9 & 110 & 1566 & -2.3 & -54.19 & 196.18 \\
\hline Sapozhnikova & 114 & 1769 & -1.50 & -500 & 44.49 & 110 & 1500 & -1.73 & -473.25 & 135.59 \\
\hline
\end{tabular}

${ }^{\mathrm{a}}$ Is obtained using the ensemble mean temperature (from 33 20C3M runs)as forcing.

[2005]. The reference states given here are sometimes quite different from those given by Oerlemans [2005], however, the length perturbation and temperature forcing values at year 1900 is close enough to what we have inferred from the temperature forcing and the glacier length observations. The retrievals are also successful, measured by the decrease in the initial guessed RMS errors in glacier lengths. For Chogo Lungma, Geblera, Maliy Aktru, Minapin, Rodzevicha, and Sapozhnikova, the initial guessed glacier length trajectories have RMS errors of about $3767,811,273,1891,2383$, and $1520 \mathrm{~m}$, respectively. Upon convergence, they are reduced to insignificant amounts of about 178.3, 61.35, 27.02, $466.0,136.9$, and $44.49 \mathrm{~m}$, respectively. In columns 6 and 11, the RMS errors (against the observed length fluctuations) are listed for the predicted $L^{\prime}$ using Oerlemans [2005] parameter values and our retrieved parameter values. For Minapin and Bolshoy Maashey, Oerlemans estimations are slightly better than our retrieval. For the remaining five, our retrieval perform better than Oerlemans [2005]. Although in most cases the two methods agree quite well, the technique described here avoids the empirical determination of the reference states and allows for integration from any arbitrarily initial time.

[29] The fact that the same temperature forcing can be applied to all seven glaciers indicates that all of them experienced similar low frequency temperature variations. This agrees with the assertion by Oerlemans [2005]. The different initial values at year 1900 indicates that they have different responses due to their respective $\tau$ and $c$.

[30] We also performed parameter retrieval using 20C3M model ensemble mean temperature anomaly (against the same reference period and averaged over the same region as with the HadCRUT3) time series. As expected, the effects of the differences between the modeled and observed 20th century temperature are manifest in differences in the retrieved parameters. However, except for Chogo Lungma, the other glaciers are not significantly affected. This is apparently due to Chogo Lungma's small slope angle and the associated large climate sensitivity $(\sim 6000$ compared with $<3000 \mathrm{~m} / \mathrm{K}$ for the remainder). We noticed that the other three retrieved parameters changed from 52 year, $0 \mathrm{~K}$ and $-44 \mathrm{~m}$ to 180 year, $0.805 \mathrm{~K}$ and $59 \mathrm{~m}$. Large climate sensitivity sacrifices the optimal determination of the response timescale $\tau$ most severely. Therefore there is uncertainty in the true response timescale from the retrieval results for this glacier. Considering that it resides in the Monsoon region and may have large mass balance gradient, it is possible that the response timescale is larger than 52 years but it is unlikely to be as long as 180 year. In Figures $5 \mathrm{a}$ and $5 \mathrm{~b}$, we noticed that the fitting for the retrieval using the model ensemble mean temperature as forcing is not as good for the earlier part of the assimilation window.

[31] The glacier responds to a smoothed temperature series. We thus compared low-pass filtered [Karoly et al., 2003] area-weighted temperature time series from the ensemble model mean (of all 33 20C3M runs), HadCRUT3 and GHCN (Global Historical Climatology Network, Easterling et al. [1996]), as shown in Figure 5c. We clearly see that both observations are close to each other but significantly warmer than the model ensemble mean before year 1960. Afterward, the three are close to each other and all reside well within the upper and lower limits set by the multi20C3M runs. Because of the high agreement between the three data sources after 1960, it was decided to use the observed temperature as forcing in retrieving the model parameters and initial states and then run an extended period with forcing from ensemble mean CGCM temperature for the next century. Specifically, we decide to make the extended runs starting from year 1900, using observed temperature and switch to SRES A2 runs after year 2000. This is especially important for sensitive glaciers such as Chogo Lungma.

[32] The transient climate we will experience over the next century is critical in that it provides us with a chance to compare the predictions for different scenarios and provides a longer-term predictability that could prove to be valuable to minimize the impact of increased mountain glacier melting. The following is a rough estimate of the warming effects, based on the SRES A2 scenario, which is a strong emission scenario suggesting a $\mathrm{CO}_{2}$ concentration of 800 ppmv by year 2100 . With the retrieved parameters and the SRES A2 temperature series, we made a prediction for each of the glacier length variations, as shown in Figure 6a. Clearly there is further retreat of the glaciers for the upcoming 50 years. The Chogo Lungma retreated most because of its large climate sensitivity. Using the upper and lower limits of the temperature time series, the uncertainty in estimation (relative that of year 2000) is calculated and given in Figure 6b. We can see that the uncertainty level is small compared to the reduction in the glacier length.

[33] By year 2060, the glacier Minapin shows the most apparent length reduction among the seven, about $5 \mathrm{~km}$ shorter than its year 2000 length of $18 \mathrm{~km}$. The smallest 

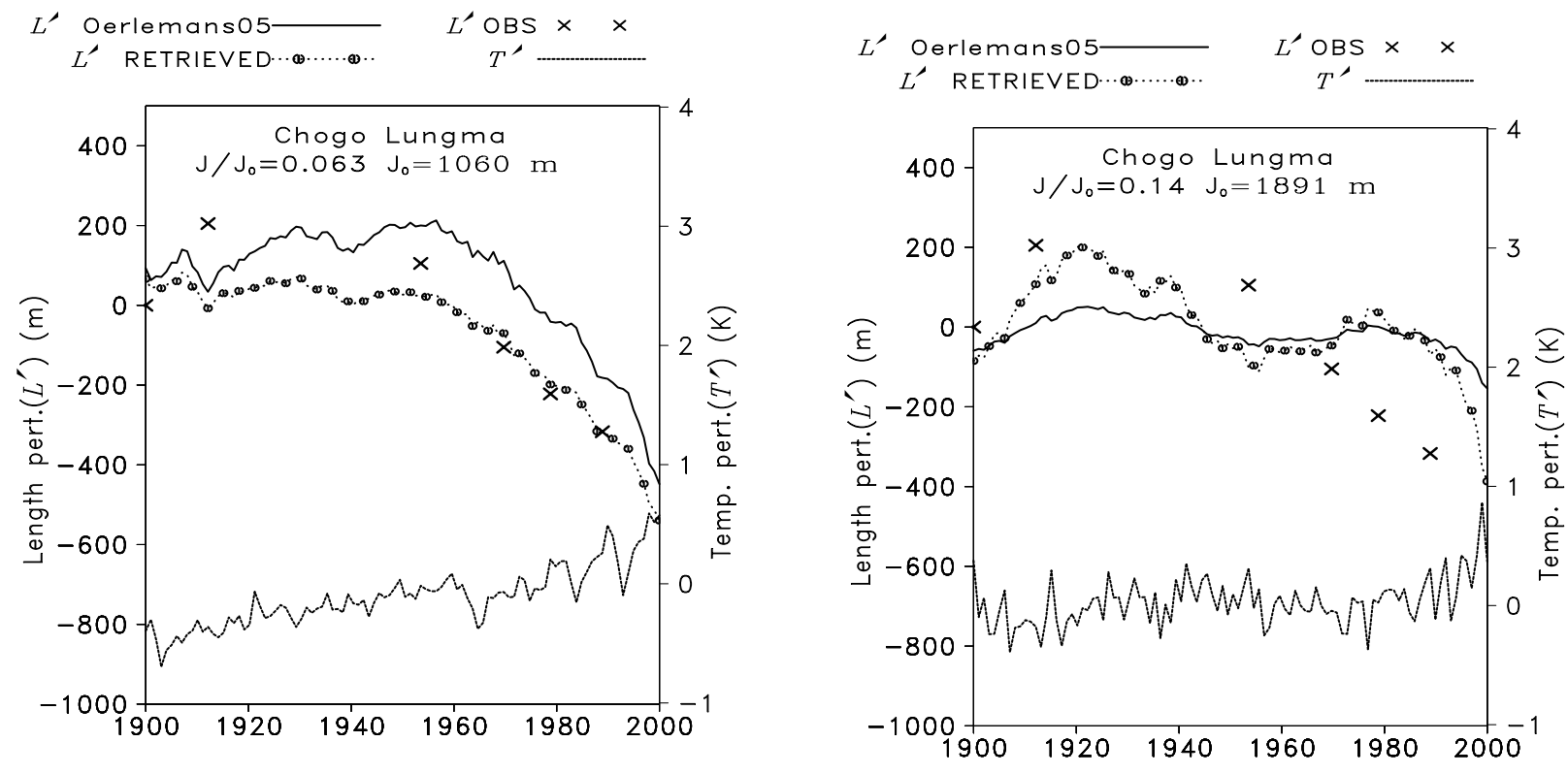

(b)

(a)

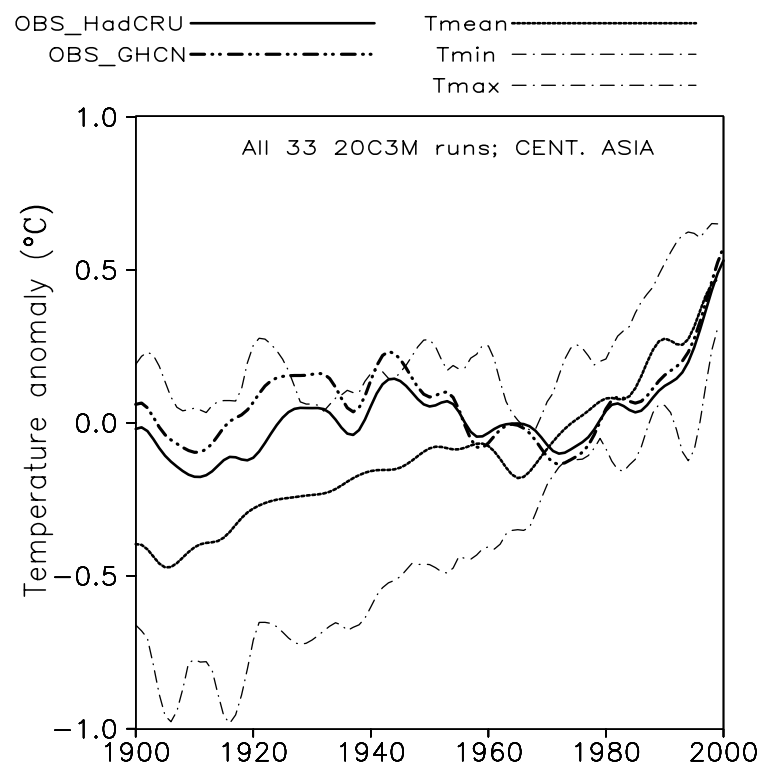

(c)

Figure 5. (a) and (b) Same as Figure 3 but for glacier Chogo Lungma. Temperature anomaly in Figure 5a is the ensemble mean of $3320 \mathrm{C} 3 \mathrm{Ms}$. Temperature anomaly in Figure 5b is the HadCRUT3 observations. (c) The two temperature series (low-pass filtered) (Figures 5a and 5b) are compared. For the modeled temperature, the upper and lower limits from the multimember model ensemble are also shown.

length reduction is from the glacier Maliy Aktru $(<1.5 \mathrm{~km}$ reduction). Interestingly, both reductions are roughly one third of their original lengths. Because of its large size ( $\sim 45 \mathrm{~km}$ ), the glacier Chogo Lungma is the least threatened. Because of the relatively flat glacier bed and the corresponding stronger front reaction, further temperature increases are primarily manifested as area shrinkage for glacier Chogo Lungma. Limited by the linear assumption, we could not make predictions further into the future [Oerlemans et al., 1998].

\section{Conclusions}

[34] In accordance with Ohmura et al. [1996], Meier et al. [2007] showed that in terms of sea level rise contributions, mountain glaciers and ice caps are likely to dominate over Greenland ice sheet throughout the next century. Accurate 

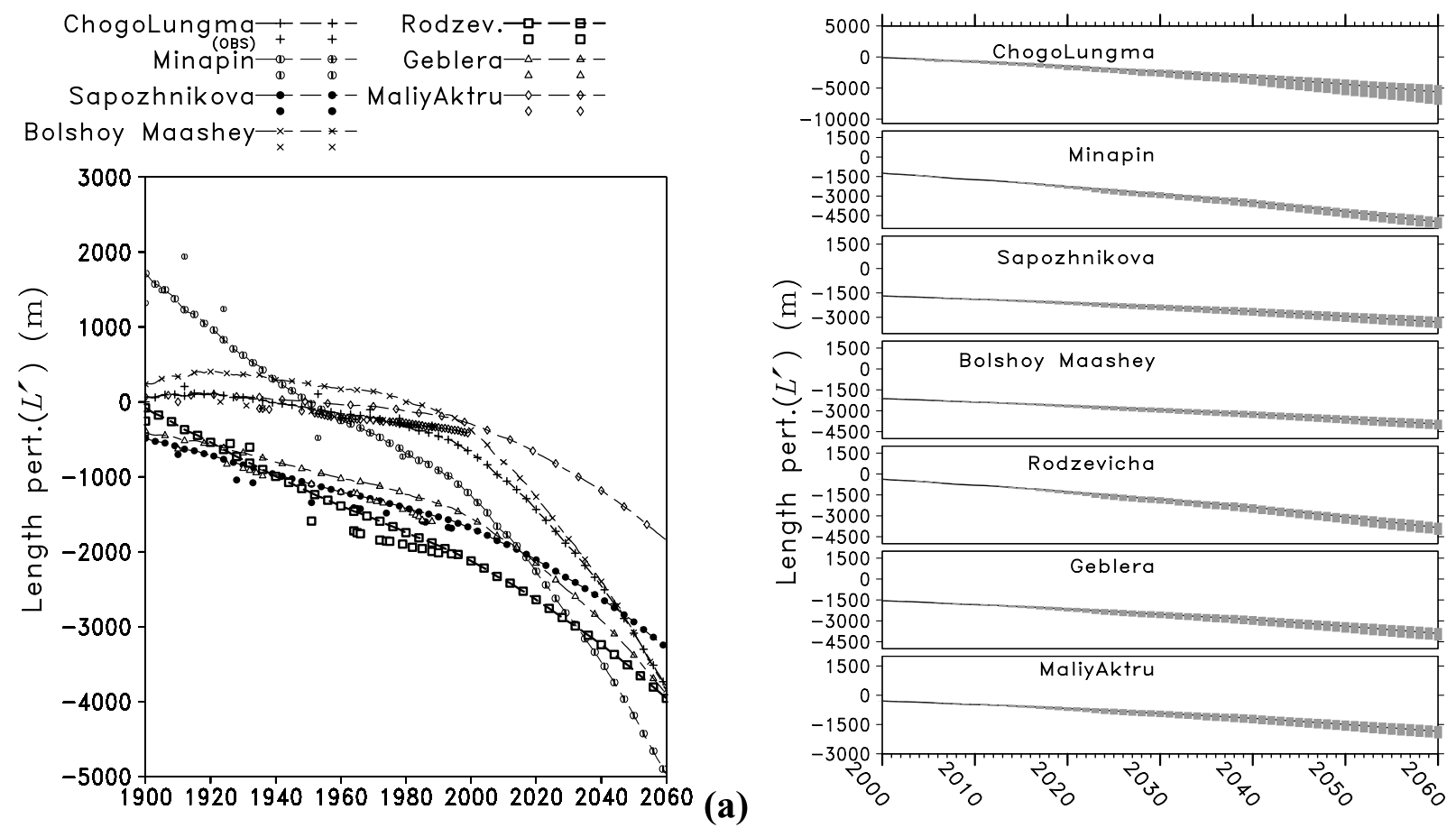

(b)

Figure 6. (a) Estimated glacier length perturbation for the upcoming 50 years. Marker-only signifies the corresponding observed glacier length perturbations. (b) The uncertainty level in the estimate after year 2000. The upper and lower limits in the temperature forcing from the multimodel ensemble are used to estimate the uncertainty level.

estimation of the climate response of mountain glaciers to a warming climate is thus vital for estimation of Earth's sea level rise. Recent glaciometeorological field experiments and modeling studies have led to a much improved understanding of the link between climate processes and individual glacier mass balance, and even the relationship with glacier geometry [e.g., Oerlemans, 2005]. With a proposed force-restore relationship, Oerlemans [2005] successfully retrieved a temperature signal from glacier length variations, without any a priori information from meteorological observations or models. This study used the same forward model but aimed to make predictions of future glacier lengths, using existing glacier and meteorology data in the best possible way. A variational retrieval scheme was used to infer the key glacier dynamical parameters, the initial value of glacier length perturbation, and the initial value of temperature forcing. We then extended the method introduced by Oerlemans [2005] and made it suitable for using currently available CGCM output to predict future glacier length fluctuations.

[35] To test the variational retrieval scheme, we systematically performed OSSE experiments where glacier length is produced using prior known temperature series. The temperature series was constructed to mimic the transient climate: a linear trend period followed by sinusoidal oscillation. In the first OSSE experiment, we systematically reduced the data availability from full 100 to merely 6 data values and found the retrieval system is always robust and successful. A second set of OSSE experiments assessed the sensitivity to Gaussian noise added to observations. An additional issue of which period of observations is more informative (for retrieval purposes) was also discussed.
[36] For perfect observations, the retrieval scheme proved to be robust for initial guess error amplitude. Specifically, the initial guess errors in $\tau$ can be as large as 5 times the actual value. The scheme works for initial guess climate sensitivity $c$ lying between $0.3 \sim 1.5$ times the true value. This range of $c$ is large and practical considering that it actually brackets the range for all types of glaciers [Oerlemans, 2005]. The retrieval scheme is robust to white noise errors in the observations of glacier length. Random error of standard deviation $<100 \mathrm{~m}$ does not adversely impact the retrieval as long as we have more than 12 data values evenly distributed. We also find that the climate sensitivity parameter is most sensitive to noise level, followed by $T_{0}, \tau$, and $L_{o}$, in this order. Also, observations collected during the earlier, larger temperature warming trend portion of the assimilation window seem to be more informative for the retrieval.

[37] We then further performed retrieval experiments using actual glacier length observations and 20th century temperature series from three different sources as forcing, and compared the retrieval results. For six out of the seven glaciers, the ensemble mean temperature from $20 \mathrm{C} 3 \mathrm{M}$ simulations are interchangeable with the HadCRUT3 and the GHCN observed temperatures. However, for Chogo Lungma, due apparently to its large climate sensitivity, the retrieval parameter estimates are sensitive to the temperature forcing. Our retrieved parameters are comparable with the values provided by Oerlemans [2005]. The technique described here, however, gives the flexibility for integration from an arbitrary initial time and saves the empirical determination of the reference states.

[38] Using the retrieved model parameters for glaciers, we made a prediction of future glacier length perturbations 
under SRES A2 scenario for temperature warming. The propagation of estimation error is also quantified using the ensemble CGCM runs. All seven glaciers are predicted to experience significant length reduction in the upcoming 50 years, especially for those with gentle slope and that reside in the Monsoonal region to the south (e.g., glacier Chogo Lungma). The reduction in glacier length clearly stands out from the associated uncertainties in estimation. However, the extra melting resulting from global warming does not threatened the existence of these seven studied glaciers by year 2060 .

[39] The overall retreat of the mountain glaciers in this region agrees with a one-dimensional flow line model results of Smedt and Pattyn [2003] for the glacier Sofiyskiy $\left(49.78^{\circ} \mathrm{N}, 87.77^{\circ} \mathrm{E}\right)$, a low elevation glacier located in the Altai mountains. Because of the low elevation, the warming from last 30 years has already moved the glacier far from a balance state, as the volume reduction will be greater than $25 \%$ of its year 2000 value by year 2100 even if the current temperature remains constant.

[40] We tested the retrievals for only 7 Asian glaciers because these were the only glacier length data readily available. The retrieval scheme itself is generally applicable for other mountain glaciers. One caveat for this study lies in the forward linear model itself. Linear glacier models, such as the one used herein with constant climate sensitivity and response timescale, should be used only for relatively small length perturbations, e.g., $L_{\text {ref }}^{\prime} / L<0.3$, because the characteristics of the glaciers, such as volume size, steepness of the bed, surface energy balance and the associated mass turnover time, and the surface slope may be changed by larger perturbations.

[41] As pointed out by one reviewer, considering a variable climate sensitivity is beyond the scope of this study using the simple linear model. What we want to emphasize is that the temperature increment should, in the long run, dominate the glacier geometry change, length change in specific. For a mountain glacier to keep a length increment under warming climate, a combination of fortunate coincidences (long response time of more than a century, large accumulation rate, and for a typical midlatitude glacier, a $25 \%$ increase in precipitation to cancel a 1 degree temperature rise) is required. That the temperature is a dominant factor is especially true for smaller, fast moving glaciers in regions where precipitation and accumulation are moderate. In this sense, receding for the four cold glaciers may be steadier than the Monsoonal ones. For example, whereas receding would be a consistent feature in the long run, glacier Chogo Lungma may advance sporadically in response to precipitation increment and/or surge caused by basal mechanism as a consequence of warming. However, we do not think that considering a variable climate sensitivity parameter will qualitatively change our conclusions drawn here.

[42] Acknowledgments. The first author is supported by a Gary Comer Science and Education Foundation Fellowship and the second author is supported by the Australian Research Council. The authors wish to express their gratitude to the four anonymous referees for their constructive suggestions. We greatly appreciate personal communications with J. Oerlemans and for providing access to his unique data sets for some Asian glaciers. We wish to thank the international modeling groups for providing their data for analysis, and the Program for Climate Model Diagnosis and Intercomparison (PCMDI) for collecting and archiving the model data.

\section{References}

Arnold, C., and C. Dey (1986), Observing-system simulation experiments: Past, present, and future, Bull. Am. Meteorol. Soc., 67, 687-695.

Brohan, P., J. Kennedy, I. Haris, S. Tett, and P. Jones (2006), Uncertainty estimates in regional and global observed temperature changes: A new dataset from 1850, J. Geophys. Res., 111, D12106, doi:10.1029/ 2005JD006548.

Dyurgerov, M., and M. Meier (2000), Twentieth century climate change: Evidence from small glaciers, Proc. Natl. Acad. Sci. USA, 97(4), 14061411.

Easterling, D., T. Peterson, and T. Karl (1996), On the development and use of homogenized climate data sets, J. Clim., 9, 1429-1434.

Errico, R. M. (1997), What is an adjoint model?, Bull. Am. Meteorol. Soc., $78,2577-2591$

Folland, C., and T. Karl (2001), The Scientific Basis, in Climate Change, edited by J. T. Houghton et al., pp. 101-181, Cambridge Univ. Press, Cambridge.

Galakhov, V., and A. M. Mukhamedov (1999), Glaciers of Altay, Novosibirsk (in Russian).

Gregory, J., and co-authors (2005), A model intercomparison of changes in the Atlantic thermohaline circulation in response to increasing atmospheric $\mathrm{CO}_{2}$ concentration, Geophys. Res. Lett., 32, L12703, doi:10.1029/2005GL023209.

Karoly, D., K. Braganza, P. Stott, J. Arblaster, G. Meehl, A. Broccoli, and K. Dixon (2003), Detection of a human influence on North American climate, Science, 302, 1200-1203.

LeDimet, F., and O. Talagrand (1986), Variational algorithms for analysis and assimilation of meteorological observations-Theoretical aspects, Tellus, 38A, 97-110.

Lord, S. J., E. Kalnay, R. Daley, G. D. Emmitt, and R. Atlas (1997), Using OSSEs in the design of the future generation of integrated observing systems, Preprint volume, 1st Symposium on Integrated Observation Systems, Long Beach, CA, 2-7 February 1997.

Meier, M. (1984), Contribution of small glaciers to global sea level, Science, 226, 1418-1421.

Meier, M., M. Dyurgerov, U. Rick, S. O'Neel, W. Pfeffer, R. Anderson, S. Anderson, and A. Glazovsky (2007), Glaciers dominate eustatic sealevel rise in the 21st century, Science, doi:10.1126/science.1143906.

Nakicenovic, N., and R. Swart (Eds.) (2000), Special Report on Emissions Scenarios (SRES), Cambridge University Press, Cambridge and New York, $612 \mathrm{pp}$.

Navon, I., and D. Legler (1987), Conjugate-gradient methods for largescale minimization in meteorology, Mon. Weather Rev., 115, 1479-1502.

Oerlemans, J. (1994), Quantifying global warming from the retreat of glaciers, Science, 264, 243-245.

Oerlemans, J. (2005), Extracting a climate signal from 169 glacier records, Science, 308, 675-677.

Oerlemans, J., et al. (1998), Modeling the response of glaciers to climate warming, Clim. Dyn., 14, 267-274.

Ohmura, A., M. Wild, and L. Bengtsson (1996), A possible change in mass balance of Greenland and Antarctic ice sheets in the coming century, J. Clim., 9, 2124-2135.

Ren, D. (2004), 4DVAR retrieval of prognostic land surface model variables for ARPS", University of Oklahoma, Norman, Oklahoma, $236 \mathrm{pp}$.

Ren, D. (2006), A modified Richards equation, its adjoint, and a new perspective on land data assimilation, Meteorol. Atmos. Phys., 92, 2532.

Ren, D., and D. Karoly (2006), Comparison of glacier-inferred temperatures with observations and climate model simulations, Geophys. Res. Lett., 33, L23710, doi:10.1029/2006GL027856.

Smedt, B., and F. Pattyn (2003), Numerical modelling of historical front variations and dynamic response of Sofiyskiy glacier, Altai Mountains, Russ. Ann. Glaciol., 37, 143-149.

Talagrand, O., and P. Courtier (1987), Variational assimilation of meteorological observations with the adjoint vorticity equation. Part I: Theory, Q. J. R. Meteorol. Soc., 113, 1311-1328.

D. J. Karoly, School of Earth Sciences, University of Melbourne, VIC 3010, Australia.

D. Ren, School of Meteorology, University of Oklahoma, 120 David L. Boren Blvd., Suite 5900, Norman, OK 73072, USA. (dd_ren@rossby. metr.ou.edu) 


\section{University Library}

\section{- M M N E R VA A gateway to Melbourne's research publications}

Minerva Access is the Institutional Repository of The University of Melbourne

Author/s:

Ren, D;Karoly, DJ

Title:

Predicting the response of seven Asian glaciers to future climate scenarios using a simple linear glacier model

Date:

2008-03-11

Citation:

Ren, D. \& Karoly, D. J. (2008). Predicting the response of seven Asian glaciers to future climate scenarios using a simple linear glacier model. JOURNAL OF GEOPHYSICAL RESEARCH-ATMOSPHERES, 113 (D5), https://doi.org/10.1029/2007JD008997.

Publication Status:

Published

Persistent Link:

http://hdl.handle.net/11343/32761 